\title{
High-surface area carbons from renewable sources with a bimodal micro-mesoporosity for high-performance ionic liquid- based supercapacitors
}

\author{
Antonio B. Fuertes, Marta Sevilla \\ Instituto Nacional del Carbón (CSIC), P.O. Box 73, Oviedo 33080, Spain \\ *Corresponding author: martasev@incar.csic.es
}

\begin{abstract}
Highly porous materials with a bimodal pore size distribution in the micromesopore range have been produced from biomass by adding melamine to the hydrochar $/ \mathrm{KOH}$ mixture used in the activation process. These carbons are characterized by BET surface areas in excess of $\sim 3300 \mathrm{~m}^{2} \mathrm{~g}^{-1}$ and a porosity equally distributed between micropores and mesopores. The use of melamine in the synthesis process not only extends the pore size distribution into the mesopore region, but leads to the incorporation of a certain amount of nitrogen atoms into the carbon framework. These materials combine high ion adsorption capacities (micropores) and enhanced ion-transport kinetics (mesopores) leading to an outstanding capacitive performance in ionic liquid-based supercapacitors. Thus, they have specific capacitances $>160 \mathrm{~F} \mathrm{~g}^{-1}$ at $1 \mathrm{~A} \mathrm{~g}^{-1}$ and $>140 \mathrm{~F} \mathrm{~g}^{-1}$ at $60 \mathrm{~A} \mathrm{~g}^{-1}$ in both pure ionic liquid and in acetonitrile-diluted ionic liquid, enabling these materials to store up to a maximum of $\mathrm{ca}$. $60 \mathrm{Wh} \mathrm{kg}^{-}$ 1 in both kinds of electrolytes and deliver ca. $20 \mathrm{Wh} \mathrm{kg}^{-1}$ at $-42 \mathrm{~kW} \mathrm{~kg}^{-1}$
\end{abstract}


(discharge time ca. $2 \mathrm{~s}$ ) in pure ionic liquid and $\sim 25-30 \mathrm{Wh} \mathrm{kg}^{-1}$ at $-97-100 \mathrm{~kW}$ $\mathrm{kg}^{-1}$ (discharge time $\sim 1 \mathrm{~s}$ ) in acetonitrile-diluted ionic liquid. 


\section{Introduction}

High surface area carbons have recently attracted much attention in relation to their use for storing energy in supercapacitors. Several types of carbon materials such as activated carbons, templated carbons, carbon nanotubes or graphene sheets have been exhaustively investigated for this purpose [1-4]. However, it is still difficult and expensive to synthesize templated carbons, carbon nanotubes or graphene on a large scale. Hence, from a practical point of view, attention has been principally focused on more conventional porous carbons that are synthesized by applying physical or chemical activation methods to abundant renewable carbon sources such as biomass-derived products. Among the conventional procedures for producing porous carbons, chemical activation is a simple and efficient method for fabricating porous carbons with very high specific surface area $\left(>2000 \mathrm{~m}^{2} \cdot \mathrm{g}^{-1}\right)$ and a large pore volume made up mainly of micropores [5]. In particular, microporous carbons produced by means of $\mathrm{KOH}$ activation of biomass-based products have attracted more and more attention in relation to their use as electrodes in supercapacitors [6, 7].

Hydrothermal carbonization is an increasingly popular technique for the synthesis of carbonaceous materials because of its simplicity, low-cost and environmental friendliness. Basically, it consists of heat-treating aqueous dispersion/dissolution of biomass-based materials at relatively low temperatures

$\left(<250^{\circ} \mathrm{C}\right)$ [8]. The resulting product, commonly denoted as hydrochar, is a highly functionalized carbonaceous substance that constitutes an excellent platform for producing more advanced materials, such as inorganic nanostructures, catalysts, porous carbons, carbon layers enveloping inorganic 
nanoparticles, etc. $[7,8]$. We recently demonstrated that hydrochar products obtained from several renewable sources (i.e. glucose, starch, cellulose and eucalyptus wood sawdust) make excellent precursors for producing highly microporous carbons by means of the chemical activation with $\mathrm{KOH}$ [9-11]. Indeed, these carbons have high specific surface areas (up to $2850 \mathrm{~m}^{2} \mathrm{~g}^{-1}$ ) and a porosity made up almost exclusively of micropores, with micropore volumes of up to $1.35 \mathrm{~cm}^{3} \mathrm{~g}^{-1}$. Firstly, we analyzed the use of such microporous carbons as sorbents for $\mathrm{CO}_{2}$ capture and as carriers for $\mathrm{H}_{2}$ storage $[9,10,12]$. More recently, we investigated the use of these carbons as supercapacitor electrodes in organic and neutral electrolytes and found that they exhibited an excellent electrochemical performance $[10,13]$.

Several authors have recently shown that the specific capacitance of porous carbons depends more on pore size rather than on surface area, with micropores in the $0.7-0.8 \mathrm{~nm}$ size range being the most suitable for achieving high energy densities [14-19]. However, carbons with a porosity made up exclusively of these narrow micropores are not a good alternative, especially for high-power applications, owing to the high ion-transport resistance in these narrow channels, which gives rise to a poor rate capability and power density values $[18,20]$. This drawback is even more pronounced when using ionic liquids (ILs) as electrolytes. Their low conductivity, high viscosity and large ion size triggers the diffusional resistance which restricts the transport of ions along the porous structure. However, ionic liquids have the advantage that they are "greener" and safer than corrosive $\mathrm{H}_{2} \mathrm{SO}_{4} / \mathrm{KOH}$ aqueous electrolytes and toxic and flammable organic electrolytes. They also allow cell voltages as high as 3.5 - $4 \mathrm{~V}$ which greatly enhances the amount of energy stored in the supercapacitor 
[21]. Therefore, a rational design of a pore architecture that combines narrow micropores (high energy density) with a certain number of mesopores is essential for reducing ion-diffusion resistance (high power density). This concept has been corroborated by Korenblit et al. by using micro/mesoporous CDC carbons as EDLC electrodes in organic electrolyte [22].

The porosity of the biomass-based $\mathrm{KOH}$ activated carbons, such as those reported by us in a previous work, is essentially made up of narrow micropores $(<1 \mathrm{~nm})$ and super-micropores $(1-2 \mathrm{~nm})$ and hardly contains any mesopores [11]. As mentioned above, this prevents these materials from being used in high-power applications. Given the importance of renewable sources for the production of porous carbons for electrochemical applications, it is clear that the production of biomass-based $\mathrm{KOH}$ activated carbons with a bimodal porosity that combines narrow micropores and mesopores is a valuable objective that, if achieved, will yield untold rewards. Accordingly, herein we present a facile one-step synthesis strategy to produce biomass-based highsurface area carbons with a bimodal porosity made up of narrow micropores $(\sim 1$ $\mathrm{nm})$ and small mesopores $(2-5 \mathrm{~nm})$. As carbon precursors, we selected two hydrochar materials obtained by hydrothermal carbonization of starch and eucalyptus wood sawdust. The procedure for fabricating the micro/mesoporous carbons involves the addition of a certain amount of melamine to the hydrochar $/ \mathrm{KOH}$ mixture used in the chemical activation. We found that the presence of melamine in this process extends the pore size distribution range of the activated carbons promoting the generation of mesopores in the $2-5 \mathrm{~nm}$ range. In addition, the presence of this $\mathrm{N}$-rich substance in the reaction mixture leads to the incorporation of a small number of nitrogen functional groups. The 
electrochemical performance of these biomass-based porous carbons was investigated by using an ionic liquid (IL) as electrolyte. We found that the mesopores generated as a consequence of using melamine notably enhances the ion transport kinetics of the bulky, low conductive and viscous ionic liquid.

\section{Experimental}

\subsection{Synthesis of Materials}

Hydrochar products were prepared by the hydrothermal carbonization of potato starch (Aldrich) and eucalyptus sawdust (Local sawmill). Briefly, an aqueous solution/dispersion of the raw material (concentration: $320 \mathrm{~g} \cdot \mathrm{L}^{-1}$ ) was placed in a stainless steel autoclave, heated up to $250^{\circ} \mathrm{C}$ and kept at this temperature for $2 \mathrm{~h}$. The resulting carbonaceous solid, denoted as hydrochar, was recovered by filtration, washed with distilled water and dried at $120{ }^{\circ} \mathrm{C}$ over a period of several hours.

The hydrochar materials were chemically activated using potassium hydroxide (Sigma-Aldrich) in the presence of melamine (Aldrich). Briefly, a hydrochar sample was thoroughly ground with $\mathrm{KOH}(\mathrm{KOH} / \mathrm{Hydrochar}$ weight ratio of 4) and melamine (Melamine/Hydrochar weight ratio of 2). Subsequently, the mixture was heat-treated up to $800^{\circ} \mathrm{C}$ (heating rate: $3^{\circ} \mathrm{C} \cdot \mathrm{min}^{-1}$ ) under a nitrogen gas flow and held at this temperature for $1 \mathrm{~h}$. The samples were then thoroughly washed several times with $10 \mathrm{wt} . \% \mathrm{HCl}$ to remove any inorganic salts, washed with distilled water until a neutral $\mathrm{pH}$ was obtained and finally dried in an oven at $120^{\circ} \mathrm{C}$ for $3 \mathrm{~h}$. The activated carbons thus synthesized were denoted as $A X-M$, where $X$ refers to the raw material $(A$ : starch and $S$ : sawdust). Porous carbons were also produced in the absence of melamine by 
simple activation of the hydrochar materials with $\mathrm{KOH}(\mathrm{KOH} / \mathrm{Hydrochar}$ weight ratio $=4$ ) at a temperature of $800^{\circ} \mathrm{C}$. These samples were denoted as $A X-0$.

\subsection{Characterization}

The nitrogen sorption isotherms of the carbon samples were measured at -196 ${ }^{\circ} \mathrm{C}$ using a Micromeritics ASAP 2020 sorptometer. The apparent surface area $\left(S_{B E T}\right)$ was calculated from the $N_{2}$ isotherms using the Brunauer-Emmett.Teller (BET) method. An appropriate relative pressure range was selected to ensure that a positive line intersect of multipoint BET fitting $(C>0)$ would be obtained and $V_{\text {ads }}\left(1-p / p_{o}\right)$ would increase with $p / p_{o}[23,24]$. The total pore volume $\left(V_{p}\right)$ was determined from the amount of nitrogen adsorbed at a relative pressure $\left(\mathrm{p} / \mathrm{p}_{\mathrm{o}}\right)$ of 0.95 . The micropore volume $\left(\mathrm{V}_{\mathrm{m}}\right)$ was obtained by applying the Dubinin-Radushkevich equation [25]. The micropore size distributions were determined by means of the quenched-solid density functional theory (QSDFT) method applied to the nitrogen adsorption data and assuming a slit pore model. Scanning electron microscopy (SEM) images were obtained on a Quanta FEG650 (FEI) instrument. Transmission electron micrographs (TEM) were taken on a JEOL (JEM 2100-F) apparatus operating at $200 \mathrm{kV}$. X-ray diffraction (XRD) patterns were obtained on a Siemens D5000 instrument operating at 40 kV and $20 \mathrm{~mA}$, using CuKa radiation. X-ray photoelectron spectroscopy (XPS) was carried out on a Specs spectrometer, using Mg K a (1253.6 eV) radiation from a double anode at $50 \mathrm{w}$. Binding energies for the high resolution spectra were calibrated by setting C 1 s to $284.6 \mathrm{eV}$. The Raman spectra were recorded on a Horiva (LabRam HR-800) spectrometer. The source of radiation was a laser operating at a wavelength of $514 \mathrm{~nm}$ and at a power of $25 \mathrm{~mW}$. Elemental 
analysis ( $\mathrm{C}, \mathrm{N}$ and $\mathrm{O}$ ) of the samples was carried out on a LECO CHN-932 microanalyzer.

The dc electrical conductivity and the packing density of the carbon powders were simultaneously determined in a home-made apparatus (fourprobe method) by pressing the carbon powders between two plungers into a hollow Nylon cylinder (inner diameter of $8 \mathrm{~mm}$ ), and applying a pressure of 7.1 MPa.

\subsection{Electrochemical measurements}

Electrodes were prepared by mixing 85 wt $\%$ of active material with $10 \mathrm{wt} \%$ of polytetrafluoroethylene (PTFE) binder (Aldrich, $60 \mathrm{wt} \%$ suspension in water) and $5 \%$ Super $\mathrm{P}$ (Timcal). The electrochemical measurements were performed in two-electrode Swagelok ${ }^{\mathrm{TM}}$ type cells using stainless steel current collectors. Electrochemical capacitors were constructed using two carbon electrodes of comparable thickness ( $150 \mu \mathrm{m})$, electrically isolated by a glassy fibrous separator. As electrolyte, the ionic liquid 1-Ethyl-3-methylimidazolium bis(trifluoromethylsulfonyl)imide (EMImTFSI) (purity $=99 \%$, Ionic Liquids Technology, Germany) was selected. It was used pure and dissolved in acetonitrile (AN, 99.8\%, anhydrous, Sigma-Aldrich). The electrochemical characterization was performed using a computer-controlled potentiostat (Biologic VMP3 multichannel generator).

Electrochemical impedance spectroscopy (EIS) measurements were performed at open circuit voltage (i.e. $0 \mathrm{~V}$ ) within the frequency range of $1 \mathrm{mHz}$ to $100 \mathrm{kHz}$ and a $10 \mathrm{mV}$ AC amplitude. Plots of the dependence of the capacitance on frequency and Nyquist plots were recorded to characterize the 
impedance of the tested samples. The specific gravimetric capacitance of a single electrode, $\mathrm{C}_{\mathrm{EIS}}(\mathrm{F} / \mathrm{g})$, was calculated according to the following formula and normalized with respect to the specific gravimetric capacitance at $1 \mathrm{mHz}$ :

$$
C_{E I S}=\frac{2 \cdot \mid \operatorname{Im}(\mathrm{Z})}{2 \pi \mathrm{f} \cdot\left[(\operatorname{Im}(\mathrm{Z}))^{2}+(\operatorname{Re}(\mathrm{Z}))^{2}\right] \cdot \mathrm{m}}
$$

where $f$ is the operating frequency $(\mathrm{Hz})$, and $\operatorname{Im}(Z)$ and $\operatorname{Re}(Z)$ are the imaginary and real components of the total device resistance $(\mathrm{Ohm})$. The relaxation time constant, $\tau_{0}$, which separates the capacitive behavior and the resistive behavior of the supercapacitor, was deduced from the frequency $f_{0}$ as follows: $\tau_{0}=1 / f_{0}$, where $f_{0}$ is obtained from the real capacitance plot at $C^{\prime}=C_{1 \mathrm{mHz}} / 2$.

Cyclic voltammetry experiments (CVs) were performed between 0 and $3 \mathrm{~V}$ at increasing sweep rates from $1 \mathrm{mV} \mathrm{s}^{-1}$ to $2 \mathrm{~V} \mathrm{~s}^{-1}$. Galvanostatic charge/discharge cycling was also performed in the 0 to $3 \mathrm{~V}$ range at increasing current densities from 0.1 to $150 \mathrm{~A} \mathrm{~g}^{-1}$, based on the active mass of one electrode. The specific gravimetric capacitance of one electrode determined from the galvanostatic cycles was calculated by means of the formula:

$$
\mathrm{C}_{\mathrm{sp}}=\frac{2 \cdot \mathrm{I}}{(\mathrm{dV} / \mathrm{dt}) \cdot \mathrm{m}}
$$

where $d V / d t=$ the slope of the discharge curve $\left(\mathrm{V} \mathrm{s}^{-1}\right)$ and $m=$ mass (grams) of carbon material in one electrode.

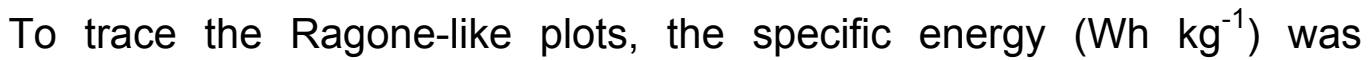
calculated using the following formula:

$$
\mathrm{E}=\frac{1}{2} \mathrm{C}_{\text {cell }} \Delta \mathrm{V}_{\mathrm{d}}^{2}
$$


where $C_{c e l l}$ is the specific capacitance of the total cell $\left(\mathrm{F} \mathrm{g}^{-1}\right)$ and $\Delta V_{d}$ is the operation voltage $\left(\mathrm{V}_{\max }-\mathrm{IR}\right.$ drop $)$.

The specific power $\left(\mathrm{kW} \mathrm{kg}^{-1}\right)$ was calculated by means of the formula:

$$
\mathrm{P}=\frac{\mathrm{E}}{\Delta \mathrm{t}_{\mathrm{d}}}
$$

where $\Delta t_{d}$ is the discharge time.

\section{Results and discussion}

\subsection{Structural and chemical properties of the porous carbons}

The microstructure and morphology of the carbon samples were examined by scanning electron microscopy (SEM). As can be seen from Figures $1 \mathrm{a}$ and $1 \mathrm{~b}$ (and Figure S1 in Supporting Information), regardless of the hydrochar used as precursor or the presence of melamine, the activated carbon particles are around $10-100 \mu \mathrm{m}$ in size and exhibit a morphology that is characterized by irregular shaped particles with large conchoidal cavities and smooth surfaces. The porosity of these carbons is made up of randomly distributed pores as illustrated by the high-resolution transmission electron microscopy (HRTEM) images in Figures 1c and 1d. The FFT (Fast Fourier Transform) patterns included in Figure 1c (inset) and Figure 1d (inset) evidence the amorphous structure of the carbon particles. This is corroborated by the XRD patterns and Raman spectra displayed in Figure 2, which show profiles typical of carbonaceous materials with an amorphous-like structure. Thus, broad and low-intensity (002) and (100) bands can be identified in the XRD 
patterns in Figure 2a, and overlapping and equal intensity $D\left(1350 \mathrm{~cm}^{-1}\right)$ and $G$ $\left(1600 \mathrm{~cm}^{-1}\right)$ bands are registered in the first order Raman spectra in Figure $2 \mathrm{~b}$.

The chemical composition of the carbon samples was determined by elemental analysis and is presented in Table 1 . The materials prepared in the presence of melamine contain a certain amount of nitrogen, i.e. $2.1 \mathrm{wt} \%$ for AAM and 1.3 wt $\%$ for AS-M. Previous results obtained in our laboratory show that during the co-carbonization of melamine and other organic materials, the melamine firstly polymerizes $\left(<500{ }^{\circ} \mathrm{C}\right)$ to carbon nitride $\left(\mathrm{g}-\mathrm{C}_{3} \mathrm{~N}_{4}\right)$ [26]. At temperatures $>550{ }^{\circ} \mathrm{C}$, the $\mathrm{g}-\mathrm{C}_{3} \mathrm{~N}_{4}$ decomposes, releasing nitrogen-containing species that react with the semi-carbonized materials thereby promoting the incorporation of $\mathrm{N}$-groups into the carbon backbone. The nature of the incorporated $\mathrm{N}$ functional groups was investigated by means of XPS analysis. Thus, the deconvoluted high-resolution $N$ 1s XPS spectrum for the AS-M sample exhibits three peaks corresponding to N-pyridinic (398.2 eV, $23 \%)$ and $\mathrm{N}$-pyrrolic/N-pyridonic (400.1 eV, $66 \%$ ), and a minor contribution at $402.3 \mathrm{eV}$ (11\%) ascribed to pyridine-N-oxides (see Figure S2 in Supporting Information). These nitrogen functional groups are characteristic of carbons that contain $\mathrm{N}$ heteroatoms incorporated into the graphene layers [27]. As will be discussed below, the chemical reactions between the melamine-based compounds and the semi-carbonized biomass products not only cause the incorporation of nitrogen functional groups, but also have a notable effect upon the textural properties of the porous carbons.

Nitrogen physisorption measurements were carried out at $-196{ }^{\circ} \mathrm{C}$ to analyze the textural characteristics of the porous carbons. The $\mathrm{N}_{2}$ sorption isotherms and the pore size distributions (PSDs) deduced by means of the 
QSDFT method are shown respectively in Figures $3 a$ and $3 c$, and Figures $3 b$ and $3 \mathrm{~d}$. The isotherm profiles of the samples synthesized in the absence of melamine (i.e. AA-0 and AS-0) can be categorized as being of type I, indicating that the porosity is mainly made up of micropores. This is confirmed by the pore size distributions for the AA-0 and AS- 0 samples shown in the Figures $3 b$ and $3 d$ respectively, which clearly show that their microporosity is made up of two pore systems in the micropore range: narrow micropores (maximum at $0.85 \mathrm{~nm}$ ) and super-micropores with a maximum at around $1.5 \mathrm{~nm}$. The textural parameters presented in Table 1 show that the AA-0 and AS-0 samples exhibit high Brunauer-Emmett-Teller (BET) surface areas of $3000 \mathrm{~m}^{2} \mathrm{~g}^{-1}(\mathrm{AA}-0)$ and $2690 \mathrm{~m}^{2} \mathrm{~g}^{-1}$ (AS-0) and pore volumes of $1.41 \mathrm{~cm}^{3} \mathrm{~g}^{-1}$ (AA-0) and $1.28 \mathrm{~cm}^{3} \mathrm{~g}^{-1}$ (AS-0). Moreover, the analysis of the porosity by means of the D-R method confirms that these samples are essentially microporous, the micropore volume constituting more than $75 \%$ of the total pore volume (see Table 1). Only a minor fraction of the porosity of these samples $(<25 \%$ of the total pore volume) can be ascribed to the small mesopores shown in Figs $3 b$ and $3 d$. By contrast, the isotherm profiles of the samples synthesized in the presence of melamine (i.e. AA-M and AS-M) combine the characteristics of isotherms distinctive of microporous carbons (i.e. large $\mathrm{N}_{2}$ uptakes at $\mathrm{p} / \mathrm{p}_{\mathrm{o}}<0.03$ ) with those typical of mesoporous materials with small mesopores (i.e. large $\mathrm{N}_{2}$ uptakes at $p / p_{o} \sim 0.1$ 0.5). This can be clearly seen in the pore size distributions in Figures $3 b$ and $3 d$, which reveal that these carbons have a bimodal porosity composed of narrow micropores $(0.85 \mathrm{~nm})$ and a large number of mesopores with a size of up to $\sim 4$ $5 \mathrm{~nm}$. The results listed in Table 1 show that these samples exhibit ultra-high BET surface areas of $3280 \mathrm{~m}^{2} \mathrm{~g}^{-1}(\mathrm{AA}-\mathrm{M})$ and $3420 \mathrm{~m}^{2} \mathrm{~g}^{-1}$ (AS-M) and large 
pore volumes of $2.37 \mathrm{~cm}^{3} \mathrm{~g}^{-1}(\mathrm{AA}-\mathrm{M})$ and $2.30 \mathrm{~cm}^{3} \mathrm{~g}^{-1}$ (AS-M). Interestingly, these carbons exhibit a good balance between the micropores $\left(\sim 1.2 \mathrm{~cm}^{3} \mathrm{~g}^{-1}, \sim\right.$ $50 \%$ of pore volume) and mesopores $\left(\sim 1.1 \mathrm{~cm}^{3} \mathrm{~g}^{-1}, \sim 50 \%\right.$ of pore volume). This is in contrast with the samples produced in the absence of melamine, whose mesopore volume is $<25 \%$ of the total pore volume. These results reveal that the addition of melamine to the synthesis mixture promotes the increase of the specific surface area and, more importantly, the enlargement of the pore size range of the $\mathrm{KOH}$-activated carbons. In this way, porous carbons with ultra-high surface areas and a bimodal porosity made up of narrow micropores and small mesopores can be easily produced from widely available biomass-derived products. It is worth noting that this effect cannot be achieved either through the increase of the activation temperature nor the amount of $\mathrm{KOH}$ in a conventional $\mathrm{KOH}$ activation of hydrochar. This is an important contribution taking into account that a porous network combining micropores and mesopores is highly advantageous in relation to the use of carbon materials as supercapacitor electrodes with bulky electrolytes. On the other hand, the textural characteristics of these materials are similar to those of polypyrrolederived activated carbon synthesized in a previous work [28]. Both methodologies share the utilization of a $\mathrm{N}$-rich precursor (polypyrrole $\mathrm{N}$ content $\sim 15 \mathrm{wt} \%$ ) during $\mathrm{KOH}$ activation, suggesting that the volatile $\mathrm{N}$-compounds released during the pyrolysis of the organic moieties have a relevant role on the generation of mesopores.

The electronic conductivity of the powder carbons was measured using a four-probe method. The home-made apparatus employed for such measurements allowed the simultaneous determination of conductivity and 
packing density. The samples produced without melamine exhibit electronic conductivities of around $4 \mathrm{~S} \mathrm{~cm}^{-1}$ and packing densities of $\sim 0.4-0.5 \mathrm{~g} \mathrm{~cm}^{-3}$ (see Table 1). By contrast, the carbons produced with melamine show lower values of electronic conductivity $\left(1.3 \mathrm{~S} \mathrm{~cm}^{-1}\right)$ and packing density $\left(\sim 0.3 \mathrm{~g} \mathrm{~cm}^{-3}\right)$. The reduction of the packing density of the carbons produced in the presence of melamine is coherent with the remarkable increase in their pore volume which, in addition, gives rise to an important loss of the intraparticle connectivity that causes a diminution of electronic conductivity. Overall, the packing density values are typical of highly activated carbons [29, 30]. These biomass-derived activated carbons exhibit similar electronic conductivities to advanced carbon materials used as electrodes in supercapacitors. This is especially true in the case of the carbons produced in the absence of melamine. For example, they have values that are close to those reported by Ruoff's group for activated graphene $\left(5 \mathrm{~S} \mathrm{~cm}^{-1}\right)$ [31] or to that of an activated carbon specifically designed for supercapacitor applications, such as Supra DLC-50 $\left(4.3 \mathrm{~S} \mathrm{~cm}^{-1}\right)$.

\subsection{Electrochemical performance of the porous carbons}

The capacitive behavior of the porous carbons was studied at room temperature in a two-electrode system by using as electrolyte a pure ionic liquid (EMImTFSI) or a mixture of EMImTFSI and acetonitrile (IL/AN weight ratio=1). Figures 4 and S3 show the results of the EIS measurements performed on the discharge state at open circuit voltage, i.e. $0 \mathrm{~V}$. Regardless of the use of pure IL or an IL/AN mixture, the Nyquist plot shows a large Warburg region in the microporous carbons $A A-0$ and AS-0 (see Figures 4a-b), indicating a high intraparticle iontransport resistance (i.e. a high equivalent distributed resistance, EDR). On the contrary, ion diffusion resistance is alleviated to a great extent in the micro- 
mesoporous carbons AA-M and AS-M. These results are corroborated by the variation in capacitance with frequency, as shown in Figures S3a-b, which reveal that the relaxation time constant of the AA-M- and AS-M-based supercapacitors is around $1.4 \mathrm{~s}$ in IL/AN and $7 \mathrm{~s}$ in pure IL (see Table S1). By contrast, in the case of the AA-0- and AS-0-based supercapacitors, the time constant is around $3 \mathrm{~s}$ in IL/AN and as long as $16-18 \mathrm{~s}$ in pure IL (see Table S1). The total cell resistance determined from a linear projection of the vertical portion of the Nyquist plot at low frequencies to the real axis in Figures $4 a$ is 5.5-7 $\Omega$ for the micro-mesoporous carbons and $10 \Omega$ for the microporous carbons in the case of pure IL. When the electrolyte is the IL/AN mixture (see Figure $4 \mathrm{~b}$ ), the total resistance is $1.2 \Omega$ for the micro-mesoporous carbons and 1.7-1.8 $\Omega$ for the microporous carbons. These results reveal that the dilution of the $\mathrm{IL}$ in acetonitrile is a very effective way to diminish the total cell resistance and enhance the power performance, as will be shown later on. Another possible way to reduce the resistance, although less effective, is by increasing the temperature of the cell (i.e. up to $60^{\circ} \mathrm{C}$ ). Thus, as shown in Figures $4 \mathrm{c}$ and 4d for AS-M and AA-0 respectively, both ESR (equivalent series resistance) and EDR diminish progressively with the increase in the operating temperature and then with acetonitrile dilution, displacing the capacitive behavior on the real impedance axis towards lower values. This leads to a faster frequency response as reflected in Figures S3c-d.

The effect of the electrode thickness on capacitive behavior was studied in the case of the micro-mesoporous carbon AS-M that is characterized by a low packing density. To this end, we increased the mass loading up to a value similar to that of commercial devices. The results obtained show that by 
doubling the thickness of the electrodes and hence the carbon mass loading per electrode $\left(\sim 6.5 \mathrm{mg} \mathrm{cm}^{-2}\right)$ in AS-M, the relaxation time constant in the two electrolytes almost doubled as can be seen from Figure S4a and Table S1. This fact is a consequence of a larger EDR resistance, as illustrated in Figure S4b. However, these values are still lower than those deduced for the AA-0 and AS-0 samples (see Table S1), which proves the essential role of mesopores in the enhancement of the ion transport kinetics.

The micro-mesoporous carbons exhibit a faster capacitive response than the microporous carbons, as was shown by cyclic voltammetry experiments (CVs). This is illustrated in Figures 5a-d where the CVs obtained at large scan rates (i.e. $>20 \mathrm{mV} \mathrm{s}^{-1}$ ) for the sawdust-based porous carbons are represented (those of the starch-based carbons are shown in Figure S5). It can be seen that in the case of pure $\mathrm{IL}$ at $20^{\circ} \mathrm{C}$, even at a high scan rate of $200 \mathrm{mV} \mathrm{s}^{-1}$, the CVs of the micro-mesoporous carbons AS-M (Figure 5a) and AA-M (Figure S5a) still retain a quasi-rectangular shape with almost the same capacitance far from the transient regions, demonstrating excellent ion transportation even in the case of the bulky ionic liquid EMImTFSI (maximum dimensions of the anion and cation are respectively 0.79 and $0.76 \mathrm{~nm}$ ) [15], which also has a high viscosity (28 $\mathrm{mPa} \mathrm{s}^{-1}$ at $\left.25^{\circ} \mathrm{C}\right)$ [21] and a low ionic conductivity $\left(8.3 \mathrm{mS} \mathrm{cm}^{-1}\right)$ [21], Only at ultra-large scan rates $\left(>500 \mathrm{mV} \mathrm{s}^{-1}\right)$, does the $\mathrm{CV}$ curve become distorted. On the contrary, the microporous carbons AS-0 and AA- 0 can only withstand scan rates of up to $100 \mathrm{mV} \mathrm{s}^{-1}$ in the pure IL (see Figures $5 \mathrm{~b}$ and S5b respectively). By diluting the $\mathrm{IL}$ in acetonitrile, the capacitive performance of both kinds of materials is greatly improved, as can be deduced from the results shown in Figures 5c-d (sawdust-based samples) and S5c-d (starch-based samples), 
confirming thereby the EIS results (Figures $4 b-d$ and S3). Indeed, in an IL/AN mixture, the AS-0 and AA-0 materials are able to keep up with a scan rate of $500 \mathrm{mV} \mathrm{s}^{-1}$, whereas AS-M and AA-M keep up with ultra-large scan rates of 1-2 $\mathrm{V} \mathrm{s}^{-1}$. As already deduced from the EIS analysis, when the working temperature in pure IL is increased up to $60^{\circ} \mathrm{C}$, the electrochemical behavior is intermediate between the pure IL at $20^{\circ} \mathrm{C}$ and the IL/AN mixture (see Figure S6).

Galvanostatic charge/discharge experiments were performed in order to accurately evaluate the specific capacitance and assess the energy and power performance of the porous materials. Figures $6 a-b$ display the $C D$ voltage profiles at a high discharge current density of $40 \mathrm{~A} \mathrm{~g}^{-1}$ in the case of the micromesoporous carbons AS-M and AA-M in pure IL at $20-60{ }^{\circ} \mathrm{C}$ and in the IL/AN mixture at room temperature. The $C D$ voltage profiles for the microporous carbons $\mathrm{AS}-0$ and $\mathrm{AA}-0$ are depicted in Figure S7. By comparing the results shown in Figures 6a-b and Figure S7, it can be seen that, regardless of the kind of electrolyte used, the voltage drop -and therefore the resistance of the cell- is much smaller for the micro-mesoporous carbons (for example, it is as low as 0.16-18 V in IL/AN) than for the microporous carbons (i.e. $0.35-0.4 \mathrm{~V}$ in IL/AN), which is in agreement with the EIS results. The modification of the specific capacitance versus discharge current density in pure IL and IL/AN mixture is shown in Figures 6c-f. It can be clearly seen that the micro-mesoporous carbons exhibit a superior rate capability, especially in the case of the pure IL electrolyte. Thus, these samples are able to work up to $150 \mathrm{~A} \mathrm{~g}^{-1}$ in IL/AN retaining $\sim 85 \%$ of capacitance (see Figure $6 \mathrm{c}$ ), up to $60 \mathrm{~A} \mathrm{~g}^{-1}$ in pure IL at 20 ${ }^{\circ} \mathrm{C}$ keeping $\sim 80 \%$ of capacitance (see Figures $6 \mathrm{e}$ ) and up to $120 \mathrm{~A} \mathrm{~g}^{-1}$ in pure IL at $60^{\circ} \mathrm{C}$ retaining $75 \%$ of capacitance (see Figure $6 e$ ). In this way, the AA-M 
and AS-M samples show a specific capacitance as high as $140-150 \mathrm{~F} \mathrm{~g}^{-1}$ at an ultra-high discharge current density of $150 \mathrm{~A} \mathrm{~g}^{-1}$ in IL/AN (see Figure 6d), 140 $\mathrm{F} \mathrm{g}^{-1}$ at a large discharge current density of $60 \mathrm{~A} \mathrm{~g}^{-1}$ in pure $\mathrm{IL}$ at $20^{\circ} \mathrm{C}$ (see Figure 6f) and $\sim 130 \mathrm{~F} \mathrm{~g}^{-1}$ at an ultra-large discharge current density of $120 \mathrm{~A} \mathrm{~g}^{-1}$ in pure IL at $60^{\circ} \mathrm{C}$ (see Figure 6f). The rate performance of the AA-M and AS-M samples in pure or AN-diluted EMImTFSI at $20^{\circ} \mathrm{C}$ is comparable to that of stateof-the-art carbon materials in different ILs, such as highly porous activated graphene [31, 32], sponge-like graphene nanoarchitectures [33], carbon nanosheets [34] or 3D ordered mesoporous carbons [35] (see Table S2). On the other hand, at a discharge rate of $1 \mathrm{~A} \mathrm{~g}^{-1}, \mathrm{AA}-\mathrm{M}$ and AS-M display specific capacitances of $\sim 160-170 \mathrm{~F} \mathrm{~g}^{-1}$ in pure $\mathrm{IL}$ at $20^{\circ} \mathrm{C}$ (around $180 \mathrm{~F} \mathrm{~g}^{-1}$ at $60{ }^{\circ} \mathrm{C}$ ) and $\sim 170-180 \mathrm{~F} \mathrm{~g}^{-1}$ in IL/AN, values that are higher than those obtained, under similar conditions, for hemp-derived carbon nanosheets [34] and paper pulp mill sludge biowaste-derived activated carbons [36], and comparable to those of highly porous activated graphene (see Table S2) [31, 32].

Two representative materials, AA-M and AS-0, were selected to evaluate the stability of these carbon-based supercapacitors. To this end, long-term charge-discharge cycling experiments were carried out by using pure IL and IL/AN electrolytes. The results represented in Figures S8a-b show an approximately 85 and $90 \%$ capacitance retention over 10000 cycles at a discharge rate as high as $10 \mathrm{~A} \mathrm{~g}^{-1}$ in IL/AN and IL electrolytes respectively. In addition, it was observed that the ESR resistance increases by 11\% in IL and by $20 \%$ in IL/AN (see Figures S8c-d), reflecting their excellent stability. Similar stabilities have been reported for other advanced carbon materials used as electrodes in IL-based supercapacitors [32, 33, 37]. 
Figure 7 shows the Ragone-like plot that compares the energy and power characteristics of these carbon-based supercapacitors in pure EMImTFSI at $20-60{ }^{\circ} \mathrm{C}$, and in the EMImTFSI/AN mixture. The results in Figure 7a reveal that, for specific powers lower than $\sim 5 \mathrm{~kW} \mathrm{~kg}^{-1}$, the AS-M and AA-0 samples can store similar specific energies in the $50-60 \mathrm{Wh} \mathrm{kg}^{-1}$ range independently of the electrolyte used. However, for specific powers higher than $5 \mathrm{~kW} \mathrm{~kg}^{-1}$, the specific energy of AS-M is considerably higher than that of AA-0 owing to its much easier ion-transport capability as a result of its well-developed mesoporous network, which gives rise to higher specific capacitances and/or higher effective cell voltages (it should be remembered that $E=1 / 2 C V^{2}$ ). The highest values of specific energy and power at high rates are achieved in the AN-diluted IL. Thus, AS-M is able to deliver $30 \mathrm{Wh} \mathrm{kg}^{-1}$ at a very high specific power of $100 \mathrm{~kW} \mathrm{~kg}^{-1}$ (see Figure 7a) and AA-M $25.5 \mathrm{Wh} \mathrm{kg}^{-1}$ at $97 \mathrm{~kW} \mathrm{~kg}^{-1}$ (see Figure 7b). Moreover, Figure $7 \mathrm{~b}$ compares the energy and power characteristics of AS-M and AA-M with those of state-of-the-art carbon materials operating in the same IL electrolyte and with a smaller electrode thickness (around 50-100 $\mu \mathrm{m}$, mass loading $\sim 2 \mathrm{mg} \mathrm{cm}^{-2}$ ) [34, 36] evidencing the superior performance of the materials developed in this work. As shown in Figure $7 \mathrm{~b}$, when the carbon mass loading is increased to values closer to those used in commercial devices $\left(6.5 \mathrm{mg} \mathrm{cm}^{-2}, 300 \mu \mathrm{m}\right)$, there is a decrease in the amount of energy stored at high rates. However, the decrease is smaller than $10 \%$ for specific powers $<25 \mathrm{~kW} \mathrm{~kg}^{-1}$ and less than $30 \%$ for specific powers in the $25-$ $80 \mathrm{~kW} \mathrm{~kg}^{-1}$ range in IL/AN electrolyte. In the case of pure IL, the loss is somewhat higher (up to $\sim 50 \%$ at the highest specific power), although this could be attenuated by using higher temperatures. It is worth pointing out that 
even so the performance of the materials is still excellent (see Figure 7b). Based on that higher carbon mass loading, it can be assumed that the active carbon weight in a packaged cell would account for 25 wt. \% of the total mass $[29,38]$ and that would lead to a specific energy of $\sim 13 \mathrm{Wh} \mathrm{kg}^{-1}$ at a specific power of $2 \mathrm{~kW} \mathrm{~kg}^{-1}$ in IL/AN ( 12 Wh kg ${ }^{-1}$ at $2 \mathrm{~kW} \mathrm{~kg}^{-1}$ in pure IL), a value which doubles that of AC-based commercial devices (i.e. 5-6 Wh $\mathrm{kg}^{-1}$ ) $[39,40]$ and is even higher than that of CDC-based commercial supercapacitors (up to $10 \mathrm{Wh}$ $\left.\mathrm{kg}^{-1}\right)[41]$.

\section{Conclusions}

In summary, we have reported a novel and simple hydrothermal-based approach for producing biomass-based porous carbons with superior electrochemical storage properties when working with an ionic liquid as electrolyte. The high performance achieved is ascribed to the unique pore architecture of the activated carbons, which combines narrow micropores that guarantee a high specific capacitance with a large number of mesopores that facilitate the transport of bulky ions like those composing ionic liquids. Carbon materials with this pore structure are fabricated by adding melamine to the hydrochar $/ \mathrm{KOH}$ mixture used in the activation process. Furthermore, these carbons possess BET surface areas in excess of $\sim 3300 \mathrm{~m}^{2} \mathrm{~g}^{-1}$ and a porosity equally distributed between micropores and mesopores. The electrodes fabricated from our materials have specific capacitances in excess of $170 \mathrm{~F} \mathrm{~g}^{-1}$ at $1 \mathrm{~A} \mathrm{~g}^{-1}$ and in excess of $140 \mathrm{~F} \mathrm{~g}^{-1}$ at $60 \mathrm{~A} \mathrm{~g}^{-1}$ in pure ionic liquid at room temperature. By increasing the working temperature up to $60^{\circ} \mathrm{C}$ or diluting the ionic liquid with acetonitrile, it is possible to enhance the power characteristics of the supercapacitors. Thus, in a pure ionic liquid, these materials are able to 
deliver at room temperature ca. $20 \mathrm{Wh} \mathrm{kg}^{-1}$ at a power density of $\sim 42 \mathrm{~kW} \mathrm{~kg}^{-1}$ (discharge time ca. $2 \mathrm{~s}$ ), and at $-55 \mathrm{~kW} \mathrm{~kg}^{-1}$ (discharge time $\sim 1.3 \mathrm{~s}$ ) at $60{ }^{\circ} \mathrm{C}$. In an acetonitrile-diluted ionic liquid, the energy-power characteristics are even better, delivering $\sim 25-30 \mathrm{Wh} \mathrm{kg}^{-1}$ at a power density of $-97-100 \mathrm{~kW} \mathrm{~kg}^{-1}$ (discharge time $\sim 1 \mathrm{~s}$ ).

Acknowledgments. This research work was supported by the Spanish Ministerio de Economía y Competitividad, MINECO (MAT2012-31651), and Fondo Europeo de Desarrollo Regional (FEDER). M. S. thanks the MINECO for her Ramón y Cajal contract. 
Table 1. Physical and chemical properties of the biomass-based $\mathrm{KOH}$ activated carbons.

\begin{tabular}{|c|c|c|c|c|c|c|c|c|c|c|}
\hline \multirow{2}{*}{$\begin{array}{l}\text { Hydrochar } \\
\text { precursor }\end{array}$} & \multirow{2}{*}{$\begin{array}{l}\text { Sample } \\
\text { code }\end{array}$} & \multicolumn{4}{|c|}{ Textural properties } & \multicolumn{3}{|c|}{ Chemical composition [wt\%] } & \multirow{2}{*}{$\begin{array}{l}\text { Conductivity } \\
{\left[\mathrm{S} \cdot \mathrm{cm}^{-1}\right]}\end{array}$} & \multirow{2}{*}{$\begin{array}{c}\text { Packing } \\
\text { density }\left[\mathrm{g} \cdot \mathrm{cm}^{-3}\right]\end{array}$} \\
\hline & & $\mathrm{S}_{\mathrm{BET}}\left[\mathrm{m}^{2} \mathrm{~g}^{-1}\right]$ & $V_{p}\left[\mathrm{~cm}^{3} \mathrm{~g}^{-1}\right]^{a}$ & $V_{\text {micro }}\left[\mathrm{cm}^{3} \mathrm{~g}^{-1}\right]^{b}$ & $V_{\text {meso }}\left[\mathrm{cm}^{3} \mathrm{~g}^{-1}\right]^{\mathrm{c}}$ & $\mathrm{N}$ & $\mathrm{C}$ & $\mathrm{O}$ & & \\
\hline \multirow[t]{2}{*}{ Starch } & AA-0 & 3000 & 1.41 & 1.09 & $0.32(23)$ & 0.1 & 93.7 & 5.9 & 3.7 & 0.39 \\
\hline & AA-M & 3280 & 2.37 & 1.07 & $1.30(55)$ & 1.7 & 86.6 & 11.1 & 1.3 & 0.32 \\
\hline \multirow[t]{2}{*}{ Sawdust } & AS-0 & 2690 & 1.28 & 1.00 & $0.28(22)$ & 0.1 & 95.4 & 4.4 & 4.5 & 0.47 \\
\hline & AS-M & 3420 & 2.30 & 1.16 & $1.14(50)$ & 1.3 & 89.6 & 8.8 & 1.3 & 0.26 \\
\hline
\end{tabular}

${ }^{a}$ Pore volume at $\mathrm{p} / \mathrm{p}_{\mathrm{o}} \sim 0.95 ;{ }^{\mathrm{b}}$ Micropore volume determined by the $\mathrm{D}-\mathrm{R}$ method; ${ }^{\mathrm{c}}$ Mesopore volume deduced by the difference between the pore volume $\left(V_{p}\right)$ and the micropore volume $\left(V_{\text {micro }}\right)$. The percentage of pore volume that corresponds to the mesopores is given in parenthesis. 


\section{References}

[1] Sevilla M, Mokaya R. Energy storage applications of activated carbons: supercapacitors and hydrogen storage. Energy Environ Sci 2014;7(4):1250-80.

[2] Gu W, Yushin G. Review of nanostructured carbon materials for electrochemical capacitor applications: advantages and limitations of activated carbon, carbide-derived carbon, zeolite-templated carbon, carbon aerogels, carbon nanotubes, onion-like carbon, and graphene. Wiley Interdisciplinary Reviews: Energy and Environment 2014;3(5):424-73.

[3] Béguin F, Presser V, Balducci A, Frackowiak E. Carbons and Electrolytes for Advanced Supercapacitors. Adv Mater 2014;26(14):2219-51.

[4] Tan YB, Lee J-M. Graphene for supercapacitor applications. J Mater Chem A 2013;1(47):14814-43.

[5] Wang J, Kaskel S. KOH activation of carbon-based materials for energy storage. J Mater Chem 2012;22(45):23710-25.

[6] Wei L, Yushin G. Nanostructured activated carbons from natural precursors for electrical double layer capacitors. Nano Energy 2012;1(4):552-65.

[7] Titirici M-M, White RJ, Falco C, Sevilla M. Black perspectives for a green future: hydrothermal carbons for environment protection and energy storage. Energy Environ Sci 2012;5(5):6796-822.

[8] Titirici MM, Antonietti M. Chemistry and materials options of sustainable carbon materials made by hydrothermal carbonization. Chem Soc Rev 2010;39(1):10316.

[9] Sevilla M, Fuertes AB, Mokaya R. High density hydrogen storage in superactivated carbons from hydrothermally carbonized renewable organic materials. Energy Environ Sci 2011;4(4):1400-10.

[10] Sevilla M, Fuertes AB. Sustainable porous carbons with a superior performance for CO2 capture. Energy Environ Sci 2011;4(5):1765-71.

[11] Wei L, Sevilla M, Fuertes AB, Mokaya R, Yushin G. Hydrothermal Carbonization of Abundant Renewable Natural Organic Chemicals for HighPerformance Supercapacitor Electrodes. Adv Energy Mater 2011;1(3):356-61.

[12] Sevilla M, Falco C, Titirici M-M, Fuertes AB. High-performance CO2 sorbents from algae. RSC Adv 2012;2(33):12792-7.

[13] Sevilla M, Gu W, Falco C, Titirici MM, Fuertes AB, Yushin G. Hydrothermal synthesis of microalgae-derived microporous carbons for electrochemical capacitors. $\mathrm{J}$ Power Sources 2014;267(0):26-32.

[14] Ania CO, Pernak J, Stefaniak F, Raymundo-Piñero E, Béguin F. Solvent-free ionic liquids as in situ probes for assessing the effect of ion size on the performance of electrical double layer capacitors. Carbon 2006;44(14):3126-30.

[15] Largeot C, Portet C, Chmiola J, Taberna P-L, Gogotsi Y, Simon P. Relation between the Ion Size and Pore Size for an Electric Double-Layer Capacitor. J Am Chem Soc 2008;130(9):2730-1.

[16] Vix-Guterl C, Frackowiak E, Jurewicz K, Friebe M, Parmentier J, Béguin F. Electrochemical energy storage in ordered porous carbon materials. Carbon 2005;43(6):1293-302.

[17] Raymundo-Piñero E, Kierzek K, Machnikowski J, Béguin F. Relationship between the nanoporous texture of activated carbons and their capacitance properties in different electrolytes. Carbon 2006;44(12):2498-507. 
[18] Chmiola J, Yushin G, Gogotsi Y, Portet C, Simon P, Taberna PL. Anomalous Increase in Carbon Capacitance at Pore Sizes Less Than 1 Nanometer. Science 2006;313(5794):1760-3.

[19] Chmiola J, Largeot C, Taberna P-L, Simon P, Gogotsi Y. Desolvation of Ions in Subnanometer Pores and Its Effect on Capacitance and Double-Layer Theory. Angew Chem Int Ed 2008;47(18):3392-5.

[20] Chmiola J, Yushin G, Dash R, Gogotsi Y. Effect of pore size and surface area of carbide derived carbons on specific capacitance. J Power Sources 2006;158(1):765-72.

[21] Brandt A, Pohlmann S, Varzi A, Balducci A, Passerini S. Ionic liquids in supercapacitors. MRS Bull 2013;38(07):554-9.

[22] Korenblit Y, Rose M, Kockrick E, Borchardt L, Kvit A, Kaskel S, et al. HighRate Electrochemical Capacitors Based on Ordered Mesoporous Silicon CarbideDerived Carbon. ACS Nano 2010;4(3):1337-44.

[23] ISO 9277:2010. Determination of the specific surface area of solids by gas adsorption - BET method. Second Edition of ISO 9277, ISO. Geneva; 2012.

[24] Rouquerol F, Rouquerol J, Sing K. Adsorption by powders and porous solids: principles, methodology and applications. San Diego Academic Press; 1999.

[25] Dubinin MM. Fundamentals of the theory of adsorption in micropores of carbon adsorbents: Characteristics of their adsorption properties and microporous structures. Carbon 1989;27(3):457-67.

[26] Fuertes AB, Ferrero GA, Sevilla M. One-pot synthesis of microporous carbons highly enriched in nitrogen and their electrochemical performance. J Mater Chem A 2014;2(35):14439-48.

[27] Pels JR, Kapteijn F, Moulijn JA, Zhu Q, Thomas KM. Evolution of nitrogen functionalities in carbonaceous materials during pyrolysis. Carbon 1995;33(11):1641-53. [28] Sevilla M, Valle-Vigon P, Fuertes AB. N-Doped Polypyrrole-Based Porous Carbons for CO2 Capture. Adv Funct Mater 2011;21(14):2781-7.

[29] Gogotsi Y, Simon P. True Performance Metrics in Electrochemical Energy Storage. Science 2011;334(6058):917-8.

[30] Murali S, Quarles N, Zhang LL, Potts JR, Tan Z, Lu Y, et al. Volumetric capacitance of compressed activated microwave-expanded graphite oxide (a-MEGO) electrodes. Nano Energy 2013;2(5):764-8.

[31] Zhu Y, Murali S, Stoller MD, Ganesh KJ, Cai W, Ferreira PJ, et al. CarbonBased Supercapacitors Produced by Activation of Graphene. Science 2011;332(6037):1537-41.

[32] Kim T, Jung G, Yoo S, Suh KS, Ruoff RS. Activated Graphene-Based Carbons as Supercapacitor Electrodes with Macro- and Mesopores. ACS Nano 2013;7(8):6899905.

[33] Xu Z, Li Z, Holt CMB, Tan X, Wang H, Amirkhiz BS, et al. Electrochemical Supercapacitor Electrodes from Sponge-like Graphene Nanoarchitectures with Ultrahigh Power Density. J Phys Chem Lett 2012;3(20):2928-33.

[34] Wang H, Xu Z, Kohandehghan A, Li Z, Cui K, Tan X, et al. Interconnected Carbon Nanosheets Derived from Hemp for Ultrafast Supercapacitors with High Energy. ACS Nano 2013;7(6):5131-41.

[35] Vu A, Li X, Phillips J, Han A, Smyrl WH, Bühlmann P, et al. ThreeDimensionally Ordered Mesoporous (3DOm) Carbon Materials as Electrodes for Electrochemical Double-Layer Capacitors with Ionic Liquid Electrolytes. Chem Mater 2013;25(21):4137-48. 
[36] Wang H, Li Z, Tak JK, Holt CMB, Tan X, Xu Z, et al. Supercapacitors based on carbons with tuned porosity derived from paper pulp mill sludge biowaste. Carbon 2013;57(0):317-28.

[37] Zhang L, Zhang F, Yang X, Long G, Wu Y, Zhang T, et al. Porous 3D graphene-based bulk materials with exceptional high surface area and excellent conductivity for supercapacitors. Sci Rep 2013;3.

[38] Simon P, Gogotsi Y. Capacitive Energy Storage in Nanostructured CarbonElectrolyte Systems. Acc Chem Res 2012;46(5):1094-103.

[39] Burke A. R\&amp;D considerations for the performance and application of electrochemical capacitors. Electrochim Acta 2007;53(3):1083-91.

[40] Obreja V. On the Performance of Commercial Supercapacitors as Storage Devices for Renewable Electrical Energy Sources. International Conference on Renewable Energy and Power Quality (ICREPQ2007). Sevilla 2007.

[41] Skeleton Technologies. http://skeletontech.com. 

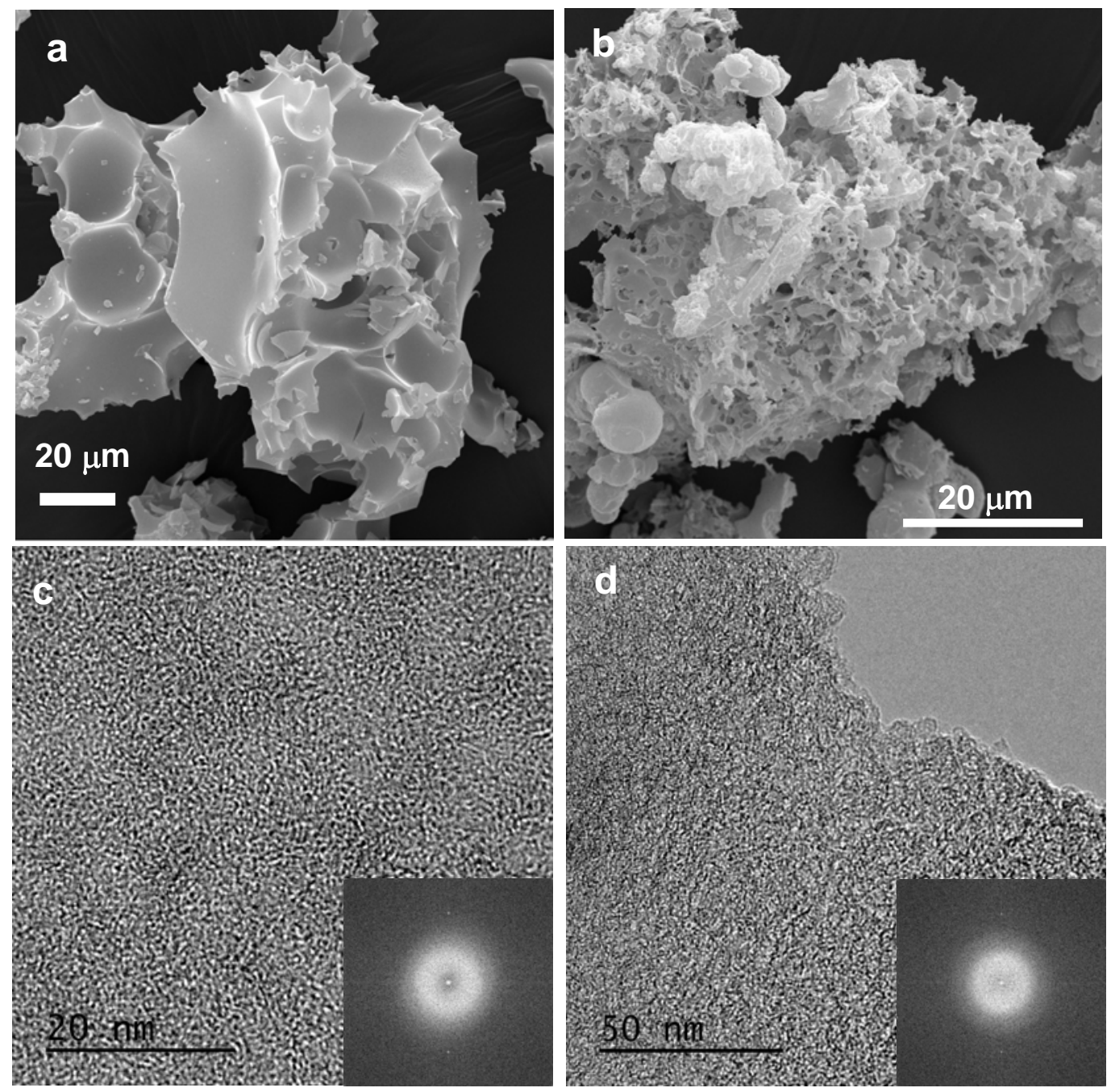

Figure 1. SEM images corresponding to (a) AA-O and (b) AA-M, and TEM images corresponding to (c) AS-0 and (d) AS-M. Insets in (c) and (d) show the FFT patterns, revealing the amorphous structure of the carbon samples. 

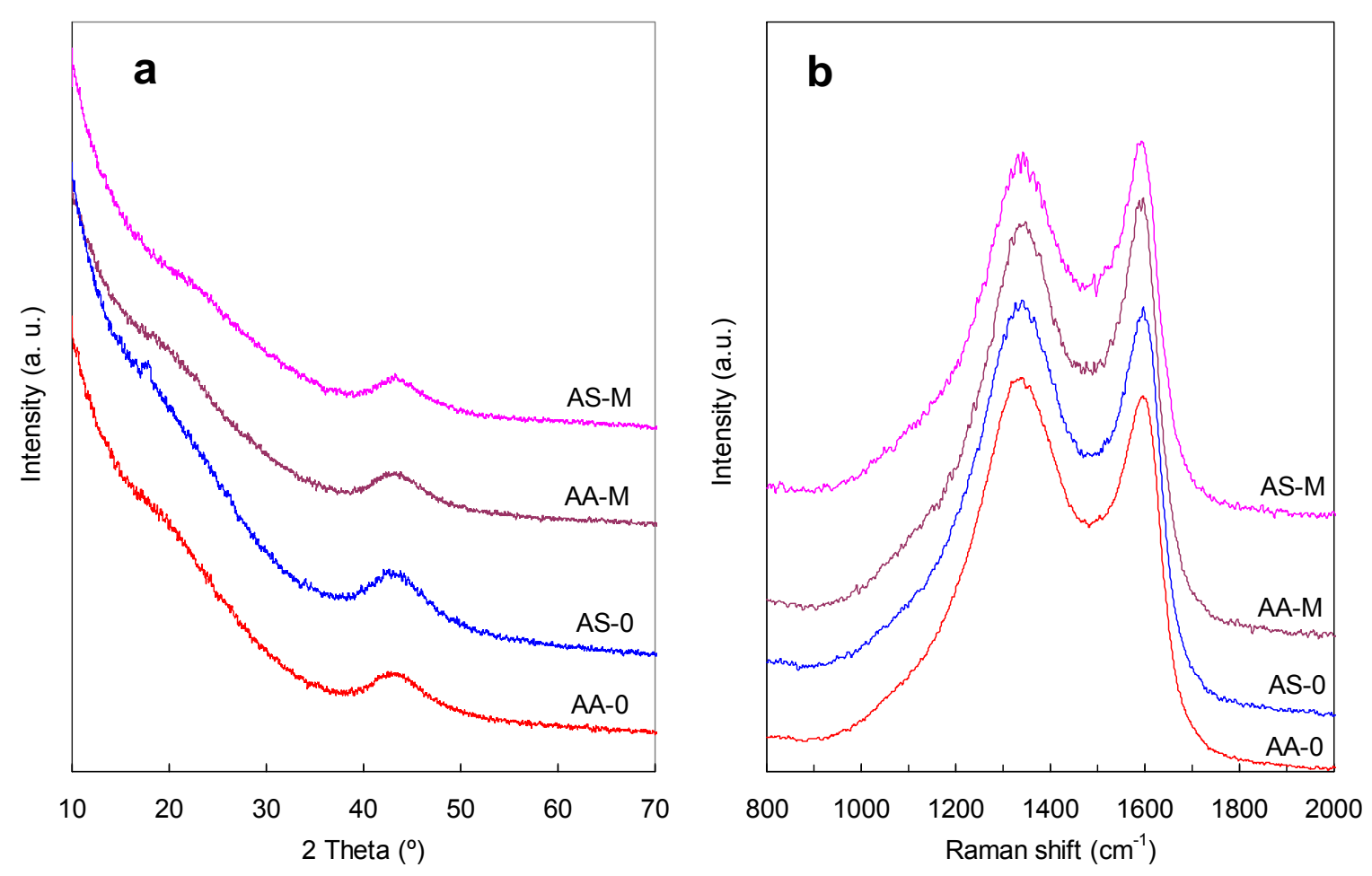

Figure 2. (a) XRD patterns and (b) Raman spectra of the activated carbon samples. 

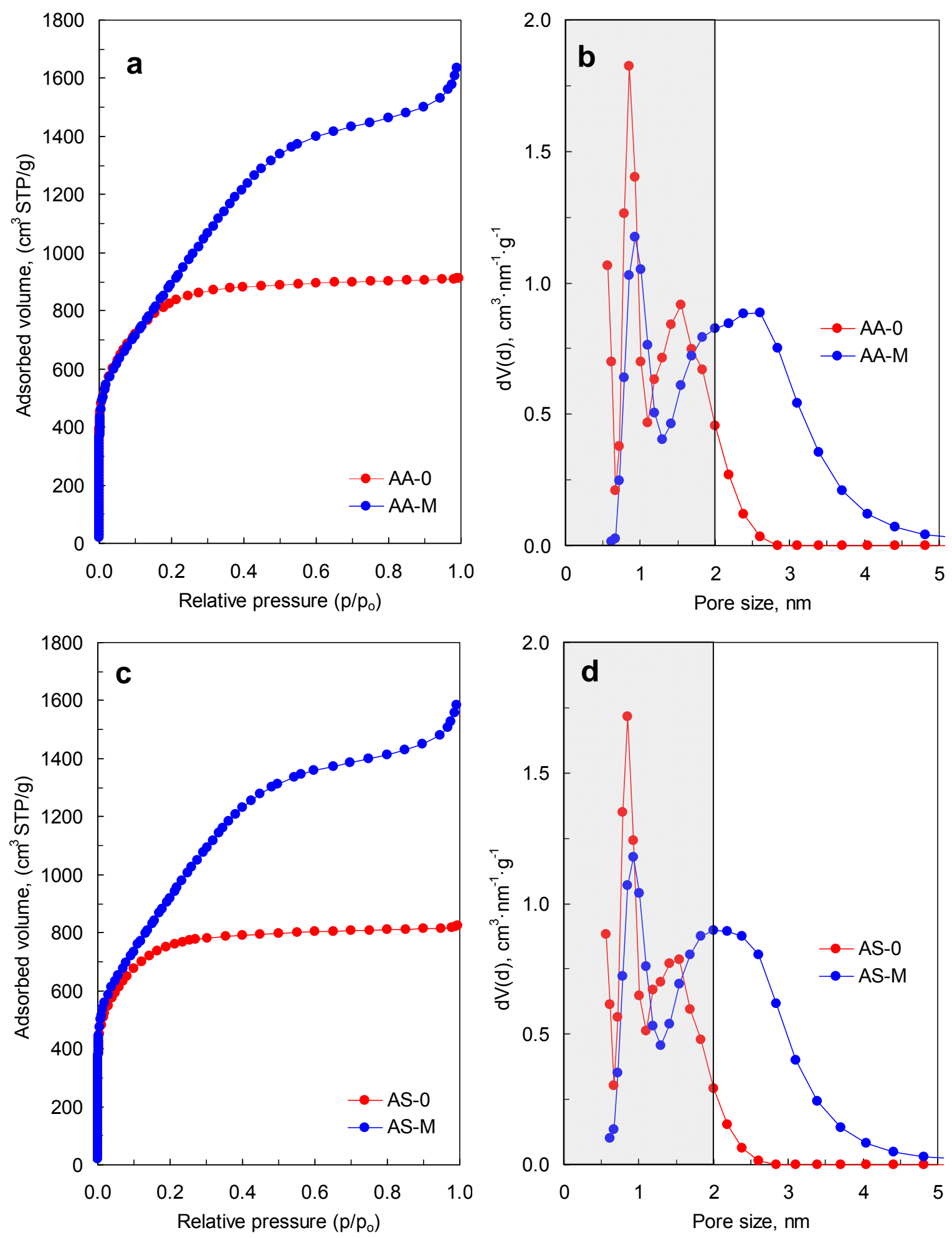

Figure 3. $(a, c)$ Nitrogen sorption isotherms and (b, d) pore size distributions deduced by means of the QSDFT method for the carbon samples prepared by $\mathrm{KOH}$ activation of hydrochar materials. The grey region corresponds to the micropore size range. 
a)

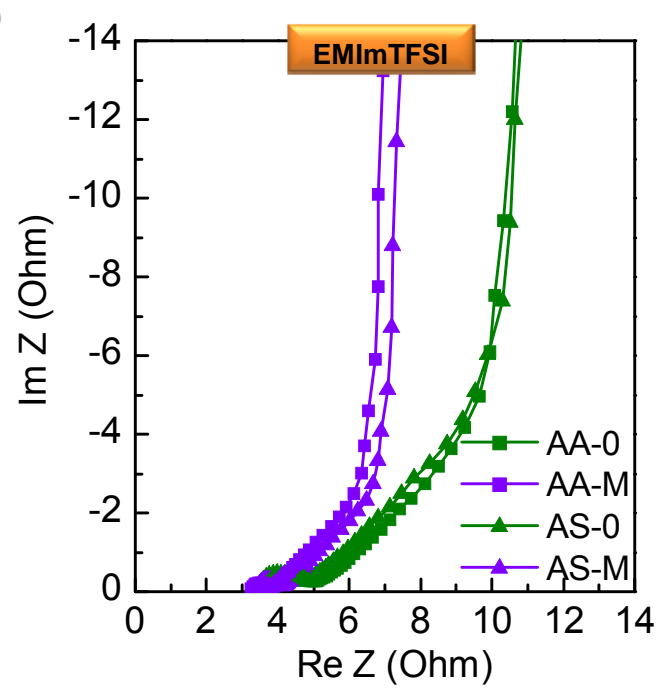

c)

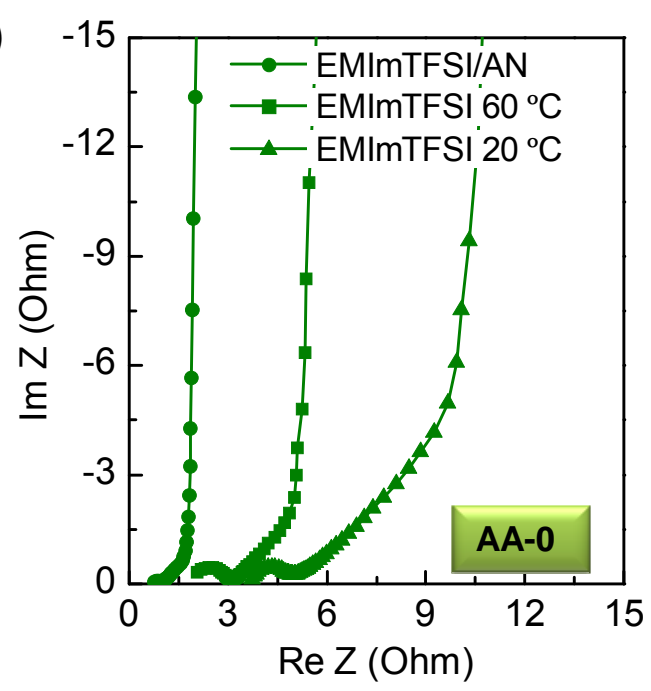

b)

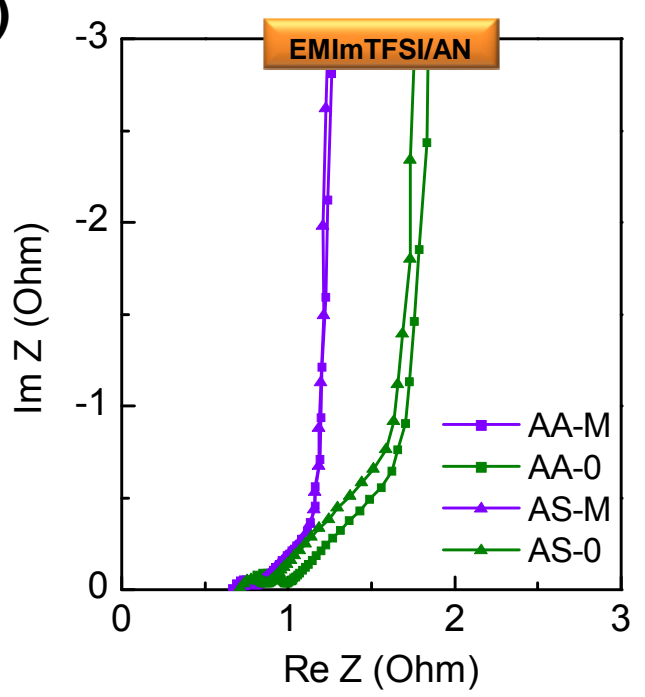

d)

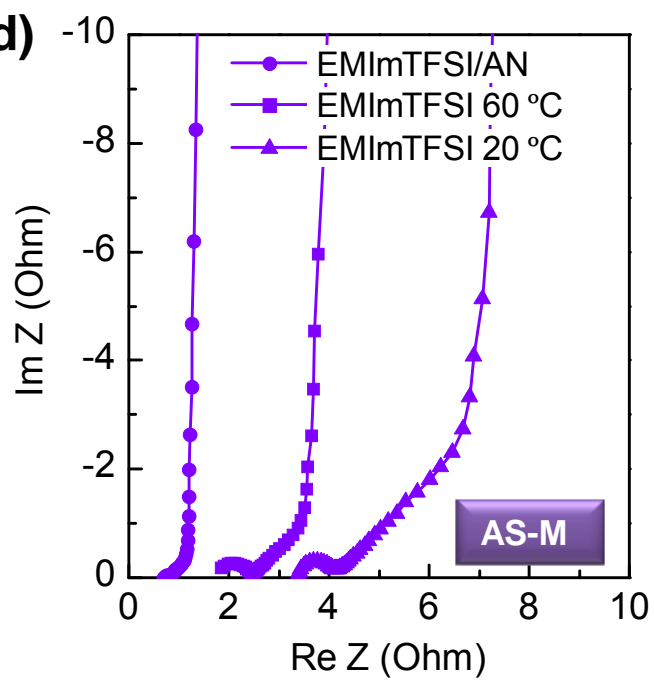

Figure 4. Nyquist plots of the porous carbons in (a) pure EMImTFSI at $20^{\circ} \mathrm{C}$ and (b) EMImTFSI/AN; impact of temperature and acetonitrile dilution of the electrolyte EMImTFSI on the impedance behavior of (c) AA-0 and (d) AS-M. 

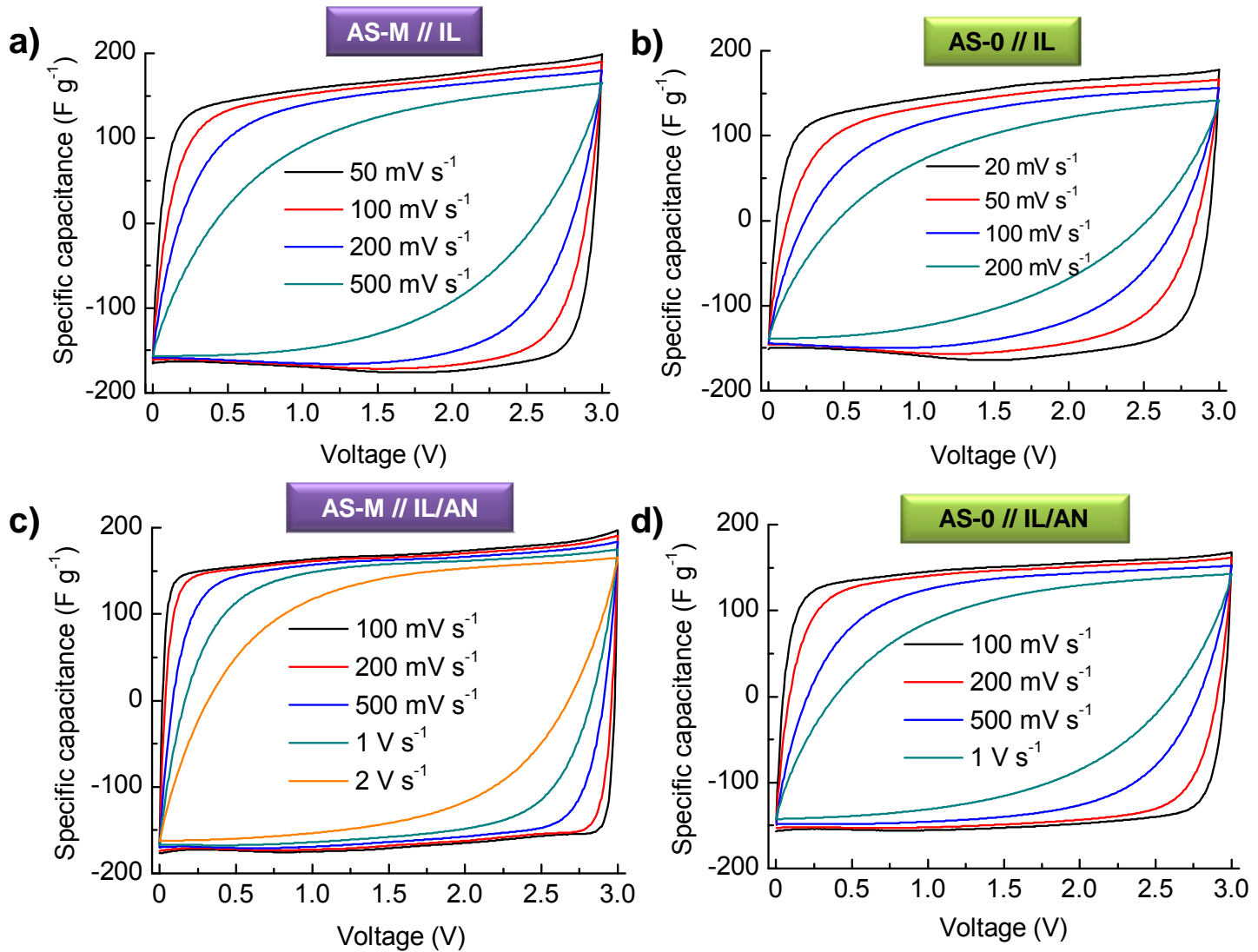

Figure 5. Cyclic voltammograms of the sawdust-based porous carbons in: $(a, b)$ pure EMImTFSI and (c, d) EMImTFSI/AN at room temperature. 
a)

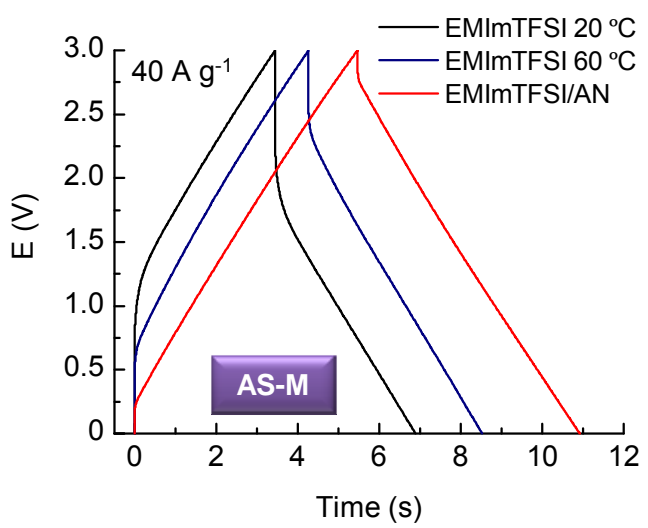

c)

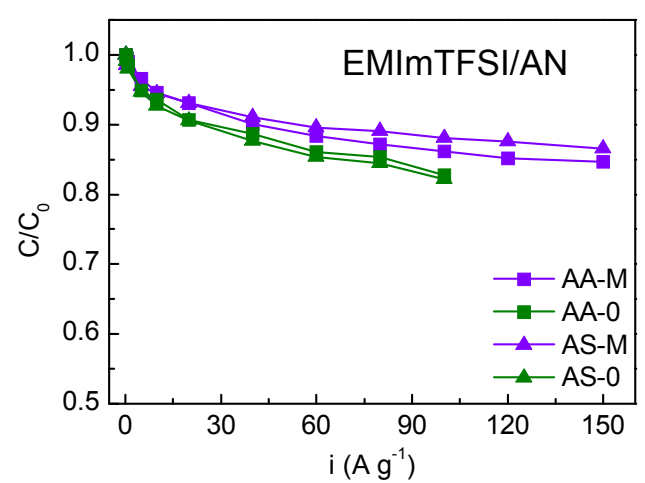

e)

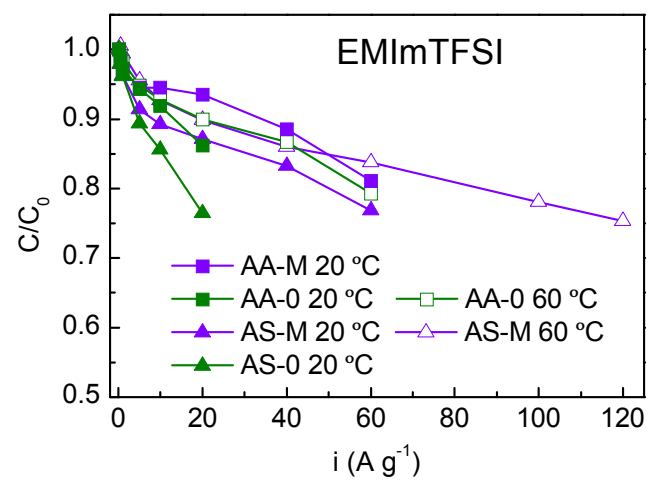

b) $3.0-$ EMImTFSI $20^{\circ} \mathrm{C}$

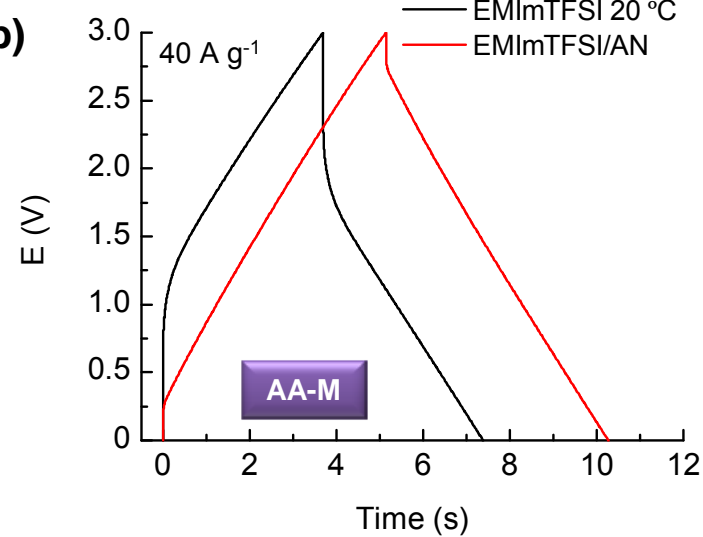

d)
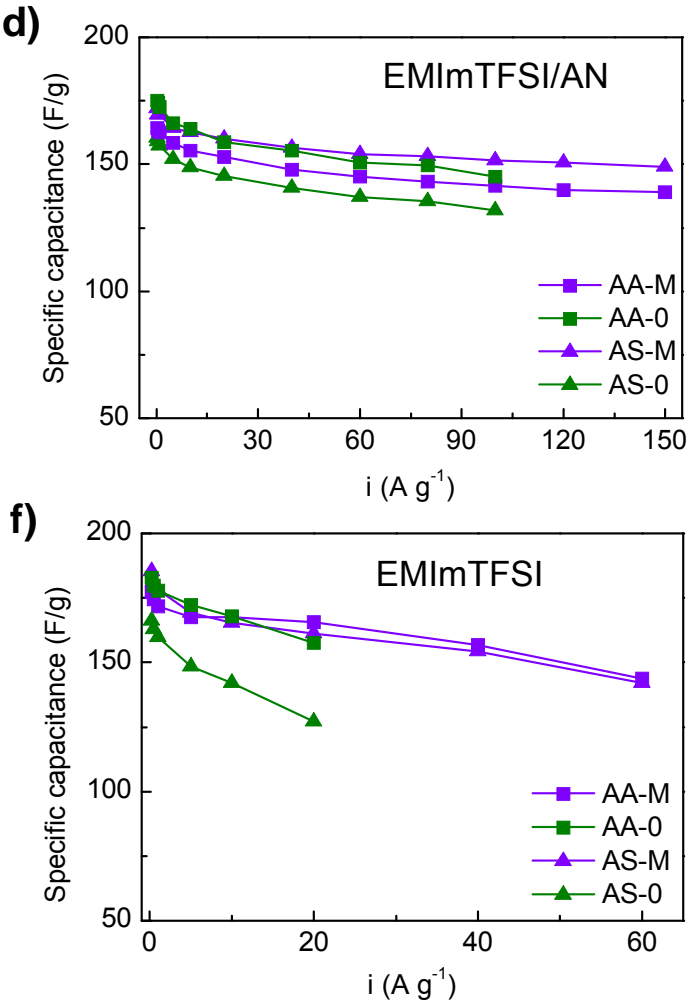

Figure 6. (a, b) CD voltage profiles of AS-M and AA-M respectively (coulombic efficiency $>99 \%$ ), (c, e) rate performance in terms of normalized capacitance $\left(\mathrm{C}_{0}=\right.$ capacitance at $\left.0.2 \mathrm{~A} \mathrm{~g}^{-1}\right)$, and $(\mathrm{d}, \mathrm{f})$ rate performance in terms of specific capacitance. 
a)

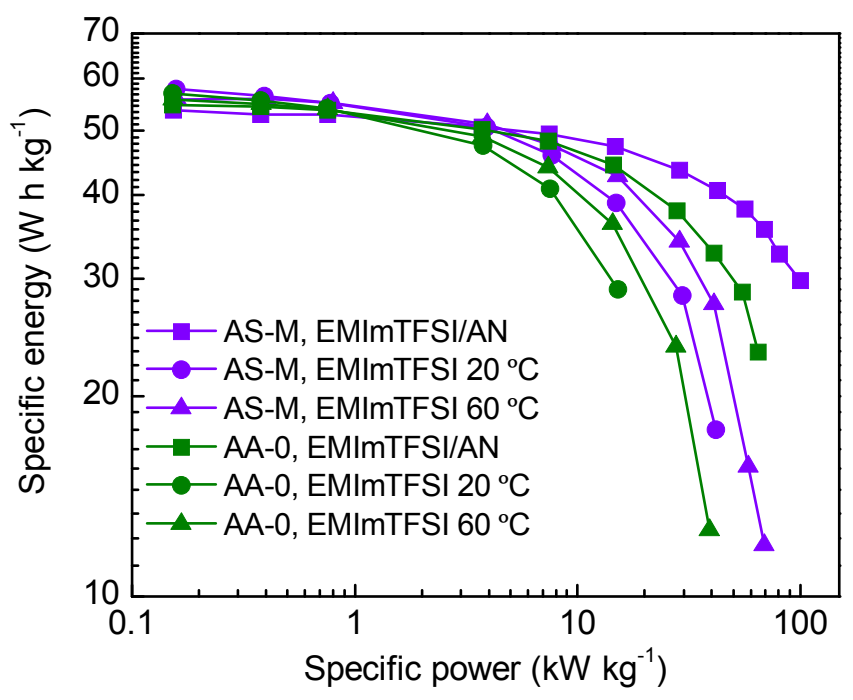

b)

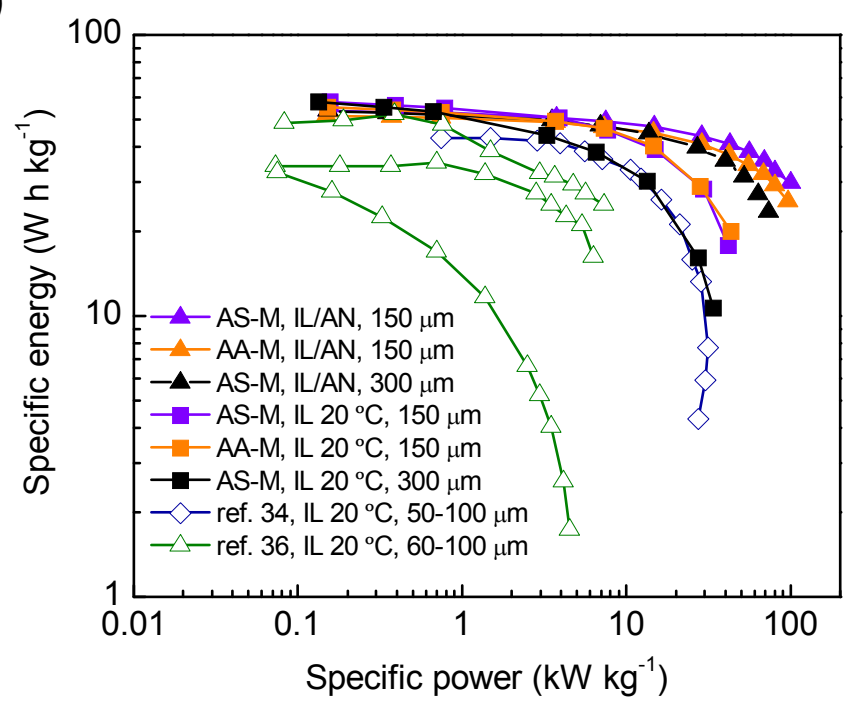

Figure 7. (a) Ragone plot corresponding to AS-M and AA-0 in IL/AN and IL at $20-60^{\circ} \mathrm{C}$, and (b) Ragone plot showing a comparison of the performance of the materials developed in this work with that of state-of-the-art carbon materials using the same pure IL electrolyte, i.e. EMImTFSI, and with a slightly lower electrode thickness (around 50-100 $\mu \mathrm{m}$, mass loading $\sim 2 \mathrm{mg} \mathrm{cm}^{-2}$ ). 